\title{
Editors' statement on considerations of biodefence and biosecurity
}

The threat of bioterrorism requires active consideration by scientists. On 9 January 2003, the US National Academy of Sciences held a discussion on the balance between scientific openness and security. The next day, a group of editors met to discuss the issues with specific reference to the scientific publication process. The following statement has emerged from that meeting. The principles discussed will be considered and followed through by Nature Medicine

The process of scientific publication, through which new findings are reviewed for quality and then presented to the rest of the scientific community and the public, is a vital element in our national life. New discoveries reported in research papers have helped improve the human condition in myriad ways: protecting public health, multiplying agricultural yields, fostering technological development and economic growth, and enhancing global stability and security.

But new science, as we know, may sometimes have costs as well as benefits. The prospect that weapons of mass destruction might find their way into the hands of terrorists did not suddenly appear on September 11, 2001. A policy focus on nuclear proliferation, no stranger to the physics community, has been with us for many years. But the events of September 11 brought a new understanding of the urgency of dealing with terrorism. And the subsequent harmful use of infectious agents brought a new set of issues to the life sciences. As a result, questions have been asked by the scientists themselves and by some political leaders about the possibility that new information published in research journals might give aid to those with malevolent ends.

Journals that dealt especially with microbiology, infectious agents, public health and plant and agricultural systems faced these issues earlier than some others, and have attempted to deal with them. The American Society of Microbiology, in particular, urged the National Academy of Sciences to take an active role in organizing a meeting of publishers, scientists, security experts and government officials to explore the issues and discuss what steps might be taken to resolve them. In a one-day workshop at the Academy in Washington on January 9, 2003, an open forum was held for that purpose. A day later, a group of journal editors, augmented by scientistauthors, government officials and others, held a separate meeting designed to explore possible approaches.

What follows reflects some outcomes of that preliminary discussion. Fundamental is a view, shared by nearly all, that there is information that, although we cannot now capture it with lists or definitions, presents enough risk of use by terrorists that it should not be published. How and by what processes it might be identified will continue to challenge us, because - as all present acknowledged - it is also true that open publication brings benefits not only to public health but also in efforts to combat terrorism.

\section{The statements follow:}

FIRST: The scientific information published in peer-reviewed research journals carries special status, and confers unique responsibilities on editors and authors. We must protect the integrity of the scientific process by publishing manuscripts of high quality, in sufficient detail to permit reproducibility. Without independent verification - a requirement for scientific progress - we can neither advance biomedical research nor provide the knowledge base for building strong biodefence system.

SECOND: We recognize that the prospect of bioterrorism has raised legitimate concerns about the potential abuse of published information, but also recognize that research in the very same fields will be critical to society in meeting the challenges of defense. We are committed to dealing responsibly and effectively with safety and security issues that may be raised by papers submitted for publication, and to increasing our capacity to identify such issues as they arise.

THIRD: Scientists and their journals should consider the appropriate level and design of processes to accomplish effective review of papers that raise such security issues. Journals in disciplines that have attracted numbers of such papers have already devised procedures that might be employed as models in considering process design. Some of us represent some of those journals; others among us are committed to the timely implementation of such processes, about which we will notify our readers and authors.
FOURTH: We recognize that on occasions an editor may conclude that the potential harm of publication outweighs the potential societal benefits. Under such circumstances, the paper should be modified, or not be published. Scientific information is also communicated by other means: seminars, meetings, electronic posting, etc. Journals and scientific societies can play an important role in encouraging investigators to communicate results of research in ways that maximize public benefits and minimize risks of misuse.

ATTENDEE LIST_Editors Meeting January 10, 2003

Ronald Atlas, President, ASM, and Editor,

CRC Critical Reviews in Microbiology

Philip Campbell, Editor, Nature

Nicholas R. Cozzarelli, Editor, PNAS

Greg Curfman, Deputy Editor,

New England lournal of Medicine

Lynn Enquist, Editor, Journal of Virology

Gerald Fink, Massachusetts Institute of Technology

Annette Flanagin, Managing Senior Editor,

Journal of the American Medical Association, and

President, Council of Science Editors

|acqueline Fletcher, President,

American Phytopathological Society

Elizabeth George, Program Manager,

National Nuclear Security Administration,

Department of Energy

Gordon Hammes, Editor, Biochemistry

David Heyman, Senior Fellow and Director of Science and Security Initiatives, Center for Strategic and International Studies

Thomas Inglesby, Editor, Biosecurity and Bioterrorism Samuel Kaplan, Chair, ASM Publications Board

Donald Kennedy, Editor, Science

Judith Krug, Director, Office for Intellectual Freedom, American Library Association

Rachel Levinson, Assistant Director for Life Sciences, Office of Science and Technology Policy

Emilie Marcus, Editor, Neuron

Henry Metzger, National Institute of Arthritis and

Musculoskeletal and Skin Diseases,

National Institutes of Health

Stephen S. Morse, Columbia University

Alison O'Brien, Editor, Infection and Immunity

Andrew Onderdonk, Editor,

Journal of Clinical Microbiology

George Poste, Chief Executive Officer,

Health Technology Networks

Beatrice Renault, Editor, Nature Medicine

Robert Rich, Editor, Journal of Immunology

Ariella Rosengard, University of Pennsylvania

Steven Salzburg, The Institute for Genome Research

Mary Scanlan, Director, Publishing Operations,

American Chemical Society

Thomas Shenk, President-Elect, ASM, and Past Editor, Journal of Virology

Herbert Tabor, Editor, Journal of Biological Chemistry Harold Varmus,

Memorial Sloan-Kettering Cancer Center

Eckard Wimmer

State University of New York at Stony Brook Keith Yamamoto, Editor, Molecular Biology of the Cell 